\title{
Optical Spectroscopic Analysis of Muscle Spasticity for Low-Level Laser Therapy (LLLT)
}

\author{
Yeon Ui Lee', Sangkwan Lee ${ }^{2}$, and Jong-In Youn * \\ ${ }^{l}$ Department of Biomedical Engineering, College of Medical Science, \\ Catholic University of Daegu, Gyeongsan 712-702, Korea \\ ${ }^{2}$ Department of Internal Medicine and Neuroscience, College of Oriental Medicine, \\ WonKwang University, Iksan 570-749, Korea
}

(Received September 9, 2011 : revised November 29, 2011 : accepted November 30, 2011)

\begin{abstract}
Current therapeutic methods for suppressing muscle spasticity are intensive functional training, surgery, or pharmacological interventions. However, these methods have not been fully supported by confirmed efficacy due to the aggravation of the muscle spasticity in some patients. In this study, a combined system was developed to treat with a low-level laser and to monitor the region of the treatment using an optical spectroscopic probe that measures oxygen saturation and deoxygenation during low-level laser therapy (LLLT). The evaluation of the wavelength dependence for LLLT was performed using a Monte Carlo simulation and the results showed that the greatest amount of heat generation was seen in the deep tissue at $\lambda=830 \mathrm{~nm}$. In the oxy- and deoxygenation measurements during and after the treatment, oxygen- $\mathrm{Hb}$ concentration was significantly increased in the laser-irradiated group when compared to the control group. These findings suggest that LLLT using $\lambda=830 \mathrm{~nm}$ may be of benefit in accelerating recovery of muscle spasticity. The combined system that we have developed can monitor the physiological condition of muscle spasticity during the laser treatment in real time and may also be applied to various myotonia conditions such as muscle fatigue, back-pain treatment/monitoring, and ulcer due to paralysis.
\end{abstract}

Keywords : Muscle spasticity, Low-level laser therapy, Optical diagnostic system, Hemoglobin concentration, Monte Carlo simulation

OCIS codes : (170.0170) Medical optics and biotechnology; (000.1430) Biology and medicine; (120.6810) Thermal effect; (170.6510) Spectroscopy, tissue diagnostics

\section{INTRODUCTION}

Cerebral palsy $(\mathrm{CP})$ is a disorder of movement and posture resulting from a non-progressive injury to an immature brain. The most common type in CP is skeletal muscle spasticity that occurs secondary to upper motor neuron lesions and can result in serious complications for affected individuals [1]. It is known that the function of individuals with spastic muscles is severely compromised due to decreased range of motion, decreased voluntary strength, and increased muscle stiffness, but the basic mechanisms underlying the functional deficits after the development of spasticity are not clearly understood [2]. Since CP affects the muscular movements of its sufferers, many medications for $\mathrm{CP}$ target the muscles for relaxation [3]. The muscle relaxants used for treating
CP work by stopping the muscles from contracting, but several side effects have been reported such as diarrhea, dizziness, drowsiness, fatigue, vague feeling of illness, and muscle weakness [3-5]. Physiotherapy such as massage has also thought to increase tissue blood circulation, thereby decreasing hypertonicity and enhancing recovery from muscle disorder [6]. Drust et al. demonstrated that there was an increase in skin and intramuscular temperature following physiotherapy, but it was not enough to increase deep intramuscular regions [7].

Recently low-level laser therapy (LLLT) has been proposed as a therapeutic tool for treating CP. LLLT $(<500 \mathrm{~mW}$, $<35 \mathrm{~J} / \mathrm{cm}^{2}$, typical wavelengths of $\left.600-1300 \mathrm{~nm}\right)$ was introduced for the management of pain, wound healing and soft tissue injury, was developed in the 1960s [8]. LLLT

*Corresponding author: jyoun@cu.ac.kr 
is a form of phototherapy that involves the application of low-power, monochromatic, coherent light to injuries and lesions [9]. LLLT has been found to accelerate wound healing and reduce pain, possibly by stimulating oxidative phosphorylation and reducing inflammatory responses, thus producing several beneficial effects upon inflammation and healing [10-17]. In skeletal muscle, LLLT has been effective at promoting improvements in electrical activity, preventing fatigue induced by tetanic contractions and improving healing after traumatic injury [11]. At the molecular level, LLLT directly stimulates the activity of cytochrome oxidase in muscle fibers, triggering a series of biochemical cascades that improve cellular functions [12].

Asagai et al. reported on the use of GaAlAs laser treatment $(\lambda=810 \mathrm{~nm})$ in a group of 1000 patients with CP. By observing infrared image and doppler ultrasonography they found that the laser reduces muscle spasm and increases the mobility of the muscles [13]. Leal Junior et al. demonstrated that LLLT with $\lambda=655 \mathrm{~nm}$ may delay the perceived onset of muscle fatigue and exhaustion through a reduction in oxidative stress or a decrease in the production of reactive oxygen species [14]. Walker et al. investigated the effects on improvement of blood flow through the autonomic nerve and the spinal reflex pathway after LLLT with $\lambda=632.5 \mathrm{~nm}$ and suggested that the mechanism of low-level laser therapy in spastic paralysis was an efferent inhibitory action and an effect on the autonomic nerve function [15]. Although many investigations have been performed for the evaluation of the effect of LLLT in muscle recovery, various laser wavelengths were treated and different results were presented. Since few studies have been done to compare photothermal effects depending on the wavelengths, Monte Carlo simulation was performed to compare different wavelengths for the effective LLLT in this study.

Recent studies have suggested that a diffuse optical signal measured over the near-infrared spectral range provides sufficient information of hemoglobin concentration and oxygen saturation in biological tissues non-invasively [18]. The advantages of near-infrared spectroscopic techniques (NIRS) include the possibility of obtaining information about the heterogeneity of local muscle metabolism with high temporal resolution [19]. Major chromophores that absorb light in living tissues are oxygenated and deoxygenated hemoglobin molecules $\left(\mathrm{HbO}_{2}\right.$ and $\mathrm{Hb}$, respectively) with distinct optical-absorption spectra in the visible and nearinfrared ranges. The ability of NIRS to quantify changes in oxygenation is based on the difference in absorption spectra for oxygenated and deoxygenated heme groups [20]. A number of different studies have evaluated the influence of increased activity as well as decreased activity on muscle function using NIRS [20-22]. Costes et al. examined exercise induced adaptations in muscles determined by NIRS and showed that training did not change the pattern of muscle oxygenation, but a significant relationship was found between blood lactate and muscle oxygenation after exercise [21].
Tiziano Binzoni et al. measured local oxygen consumption in human muscle during rhythmically contractions of exercising skeletal muscle. They found that the saturation of the blood during the contraction phase was lower than that during the relaxation phase [22].

For laser therapy applications, it is important to know the penetration and heat generation of laser in tissue in order to select optimal criteria such as wavelength, fluence, and beam size to afford the desired penetration for stimulating tissue healing in deep seated pathologies [23, 24]. LLLT has demonstrated a number of biological and clinical efficacious results for muscle treatment, but this therapy has not been fully supported by scientific evidence due to the absence of quantitative assessments and treatment feedback data in real time. In this study, a NIRS system combined with laser treatment source was developed to monitor muscle tissue conditions such as oxygen saturation and deoxygenation during laser treatment using an optical spectroscopic probe.

\section{EXPERIMENTAL METHODS}

\subsection{Laser Wavelength Dependence for LLLT using Monte Carlo Simulation}

A Monte Carlo simulation technique, based on the statistical nature of radiation interactions, has been widely applied in laser radiation transport studies [25-28]. Monte Carlo simulation methods trace the propagation of individual photons through a turbid medium until the photon experiences complete absorption by or escape from the medium [28]. In this study, the heat generation in skin was investigated by a computer simulation of appropriately weighted random absorption and scattering interactions. This mathematical modeling helps to determine the effective wavelength for deep tissue penetration in LLLT. The optical parameters of skin corresponding to the wavelengths of $660 \mathrm{~nm}, 750 \mathrm{~nm}$, $830 \mathrm{~nm}, 980 \mathrm{~nm}$, and $1064 \mathrm{~nm}$ are presented in Table 1 . The anisotropy factor for skin tissue, g, defined as the mean cosine of the deflection angle due to a scattering event, has a typical value of 0.9 [29]. These optical

TABLE 1. Optical properties of skin for Monte Carlo simulation variables

\begin{tabular}{|c|c|c|c|c|c|c|}
\hline & & $660 \mathrm{~nm}$ & $750 \mathrm{~nm}$ & $830 \mathrm{~nm}$ & $980 \mathrm{~nm}$ & $1064 \mathrm{~nm}$ \\
\hline \multirow{4}{*}{ skin } & $\mu_{\mathrm{a}}\left[\mathrm{cm}^{-1}\right]$ & 0.29 & 0.13 & 0.12 & 0.37 & 0.8 \\
\hline & $\mu_{\mathrm{s}}\left[\mathrm{cm}^{-1}\right]$ & 260 & 210 & 180 & 150 & 130 \\
\hline & $\begin{array}{l}\text { Refractive } \\
\text { Index }\end{array}$ & & & 1.44 & & \\
\hline & $g^{*}$ & & & 0.9 & & \\
\hline & $\begin{array}{l}\text { Photon } \\
\text { number }\end{array}$ & & & 10000 & & \\
\hline
\end{tabular}

$\mu_{\mathrm{a}}:$ Absorption coefficient, $\mu_{\mathrm{s}}$ : Scattering coefficient $\mathrm{g}$ : Anisotropic factor 
properties of the tissues for simulation were determined on the basis of literature values [29].

\subsection{The Combined Therapeutic Laser and NIRS System}

Near infrared light $(700 \mathrm{~nm} \sim 1500 \mathrm{~nm})$ can transmit through tissues about a few centimeters, depending on the separation between the light source and detector [30, 31]. Some of the injected NIR light is lost as a result of scattering and absorption due to different structures and optical properties in the tissue. The attenuation of light between the source and detector can be formulated by using modified Beer-Lambert's law [30, 31]. It is mathematically expressed as

$$
O D=\log \left(I_{0} / I\right)=\varepsilon c L
$$

Where, OD is the tissue's optical density, $\mathrm{I}_{0}$ is the incident light intensity, I is transmitted light intensity, $\varepsilon$ is the extinction coefficient of the chromophores $\left(\mathrm{mM}^{-1} \cdot \mathrm{cm}^{-1}\right)$, c is the concentration of the chromophores $\left(\mathrm{mM}^{-1}\right)$, and $\mathrm{L}$ is the path length of light through tissue.

By detecting the light intensity changes at two or more wavelengths in the NIR region, the changes in concentrations of deoxy-hemoglobin ([Hb]) oxy-hemoglobin $\left(\left[\mathrm{HbO}_{2}\right]\right)$ at deep tissues can be estimated as follows

$$
O D^{\lambda}=\left\{\varepsilon_{H b}^{\lambda}[H b]+\varepsilon_{H b O_{2}}^{\lambda}\left[H b O_{2}\right]\right\} L
$$

Where $\mathrm{OD}^{\lambda}$ is the optical density or absorbance at wavelength $\lambda, \varepsilon_{\mathrm{Hb}}{ }^{\lambda}$ and $\varepsilon_{\mathrm{HbO} 2}{ }^{\lambda}$ are the extinction coefficients at wavelength $\lambda$ for molar concentrations of $[\mathrm{Hb}]$ and $\left[\mathrm{HbO}_{2}\right]$, respectively.

By employing two wavelengths, it follows that changes in $[\mathrm{Hb}]$ and $\left[\mathrm{HbO}_{2}\right]$ can be consequently given as

$$
\Delta\left[\mathrm{Hb}_{\text {total }}\right]=\Delta[\mathrm{Hb}]+\Delta\left[\mathrm{HbO}_{2}\right]
$$

As seen in the Figure 1, the system consists of a diode laser source (DL8142-201, Thorlabs, Newton, NJ, USA) for LLLT and a spectrometer (USB 4000, Ocean Optics, Dunedin, FL, USA) module to monitor dynamic changes of $\mathrm{HbO}_{2}$ under the skin. The laser source is connected with an optical fiber at the center of the designed probe and the fibers for the light source and spectroscopic detection were connected at the sides of the probe. Because the thickness of the skin and adipose tissue layer in humans is approximately $3 \mathrm{~mm}$ the source-detector separation used in this study was $2 \mathrm{~cm}$, which allowed for sufficient light penetration into the muscle [32]. The incident light source was generated by a tungsten-halogen lamp (HL-2000, Ocean Optics, Dunedin, FL, USA) and the acquired signal reflected from tissue was transmitted to the spectrometer with the spectral range from 300-1000 nm. A diode laser (Power $=$

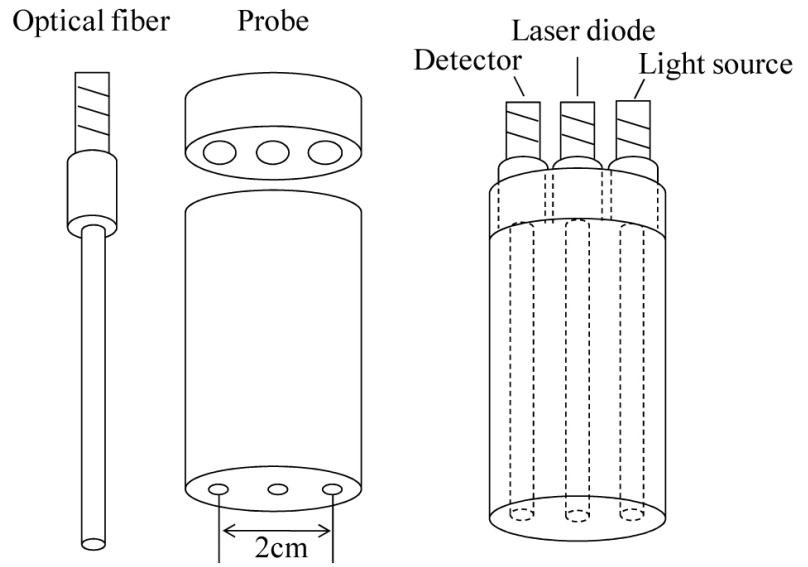

FIG. 1. The schematic diagram of the combined probe in the developed system.

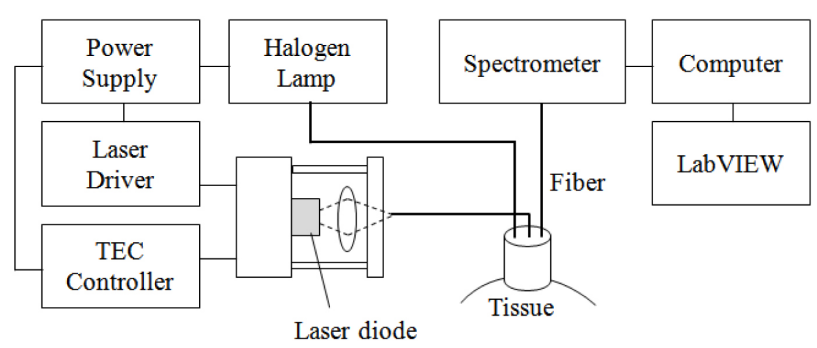

FIG. 2. The schematic diagram of the developed system that is combined with a therapeutic laser and spectroscopic system.

$80 \mathrm{~mW}, \lambda=830 \mathrm{~nm}$, spot size $=3 \mathrm{~mm}$ ) was used for the treatment of muscle spasticity (Fig. 2). This wavelength provided high contrast and deep penetration in tissue that delivers enough laser fluence for stimulating chromophores in muscle based on Monte Carlo simulation.

\subsection{Experimental Procedure}

Twenty male and female subjects between 23 and 25 years of age agreed to participate in the study through a written informed consent. All subjects were healthy and physically active students with no recent experience with isokinetic eccentric exercise. Subjects agreed not to perform physical exercise or use any other therapeutic modalities during the data collection sessions. The subjects were randomly divided into two groups: the control group and the laserirradiated group. Both groups were instructed to perform repeated elbow flexion-extension from full elbow extension to $90^{\circ}$ of flexion for 10 minutes. Prior to the experimental protocol, the relative changes of $\left[\mathrm{HbO}_{2}\right]$ and $[\mathrm{Hb}]$ concentration in normal state with the developed system were measured for all subjects. Immediately after flexion-extension exercise, the probe was placed on the trigger point in the brachioradial muscle of the left forearm, $4 \mathrm{~cm}$ distal to the elbow. A trigger point is defined as a point that elicits referred pain on deep palpation and demonstrates a lowered skin resistance in comparison with that of the surrounding 
tissue [33]. The probe was in contact with the skin at a right angle and the low-level laser at $\lambda=830 \mathrm{~nm}$ irradiated it with a power of $80 \mathrm{~mW}$. During exercise and LLLT procedure, the relative changes in oxygen and deoxygenation concentrations in hemoglobin were measured simultaneously for the subjects to monitor muscle recovery through the developed system."

\section{RESULTS AND DISCUSSION}

Figure 3 shows the relative rate of heat generation versus optical penetration depth in skin with different laser wavelengths $(\lambda=660 \mathrm{~nm}, 750 \mathrm{~nm}, 830 \mathrm{~nm}, 980 \mathrm{~nm}$, and $1064 \mathrm{~nm})$. In Monte Carlo simulation with $\lambda=660 \mathrm{~nm}$ and $1064 \mathrm{~nm}$, the greatest amount of heat is generated at
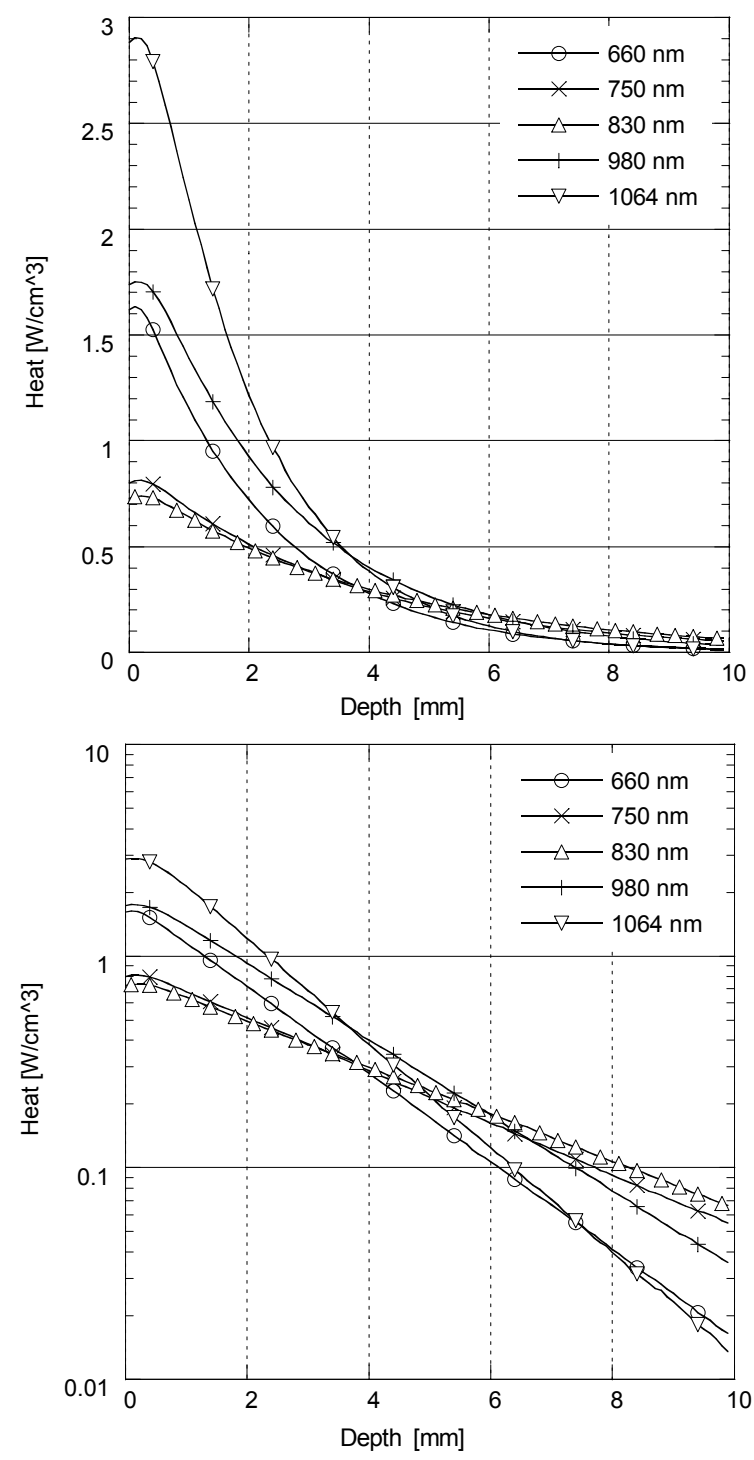

FIG. 3. The relative heat generation vs. penetration depth in skin depending on the wavelengths for LLLT using Monte Carlo simulation (left), and the log scale plot (right). the surface, but the heat is dramatically reduced as the penetration depth is increased. On the other hand, in $\lambda=$ $750 \mathrm{~nm}, 830 \mathrm{~nm}$, and $980 \mathrm{~nm}$, the rate of heat generation is less at the surface, but higher in deep tissue. The highest heat generation in deep tissue was achieved at $\lambda=$ $830 \mathrm{~nm}$ below a depth of $5 \mathrm{~mm}$. According to this result, the maximum heat generation and deep penetration for skin was achieved at $\lambda=830 \mathrm{~nm}$ for effective LLLT.

Prior to the measurements of LLLT's effect by a spectroscopic analysis, the feasibility test of the developed system was performed to see the hemoglobin concentration changes in muscle without low-level laser irradiation. The changes of oxy- $\left(\left[\mathrm{HbO}_{2}\right]\right)$ and deoxy-hemoglobin $([\mathrm{Hb}])$ concentrations were monitored by applying the occlusion of a cuff pressure around the upper arm. Figure 4 shows that the rapid increase of the cuff pressure induced rapid and substantial decrease in $\left[\mathrm{HbO}_{2}\right]$. At the same time, $[\mathrm{Hb}]$ gradually increased as a result of continuous oxygen consumption in muscle and undelivered oxygen throughout the arterial occlusion by the cuff pressure. The typical reactive hyperemia following the release of cuff pressure was much higher than the normal state of $\left[\mathrm{HbO}_{2}\right]$. This variation was primarily due to delays between venous and arterial occlusion during both pressure cuff and release cuff which leads to trapping of blood in the capillaries.

To evaluate the effect of LLLT, the subjects were divided into two groups, the control group and the laser irradiated group, and the relative changes in $[\mathrm{Hb}]$ and $\left[\mathrm{HbO}_{2}\right]$ concentrations in muscle were measured after exercise for both groups. Figure 5 shows the results of $[\mathrm{Hb}]$ for a single, typical member of each group. $[\mathrm{Hb}]$ had a significant difference between the two groups. In the laser-irradiated group, $[\mathrm{Hb}]$ concentration rapidly and dramatically decreased after the exercise. Conversely in the control group, $[\mathrm{Hb}]$ concentration decreased slowly over the time. Figure 6 shows data for a single, typical member of each group. The figure shows that $\left[\mathrm{HbO}_{2}\right]$ increased slowly to baseline level before exercise in the control group, whereas in the

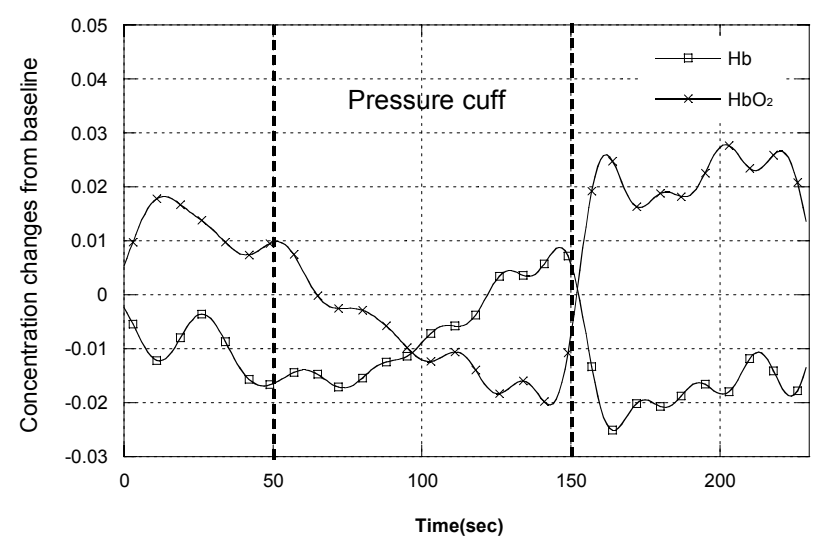

FIG. 4. The relative changes in $\left[\mathrm{HbO}_{2}\right]$ and $[\mathrm{Hb}]$ concentrations from the application of a pressure cuff: before, during and after the blood flow occlusion on a forearm. 


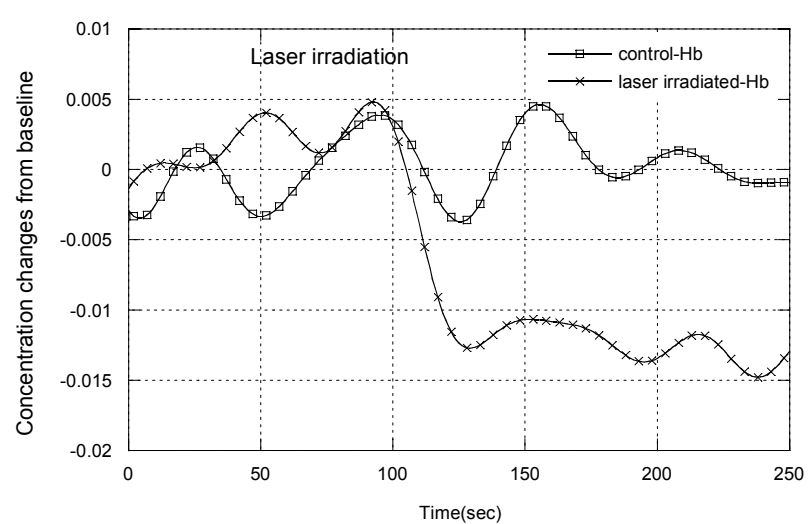

FIG. 5. The relative changes in [Hb] concentrations: post exercise for one typical member of the control group $(\square)$, and one typical member of the laser irradiated group (X).

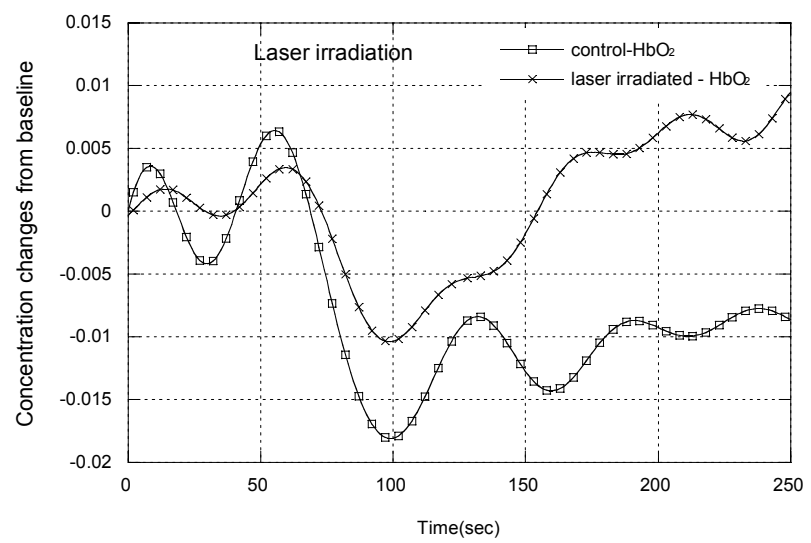

FIG. 6. The relative changes in $\left[\mathrm{HbO}_{2}\right]$ concentrations: post exercise for one typical member of the control group $(\square)$, and one typical member of the laser irradiated group (X).

laser-irradiated group, $\left[\mathrm{HbO}_{2}\right]$ increased rapidly toward their baseline level. All the participants showed similar tendencies within each group. The average relative changes in $[\mathrm{Hb}]$ before and after the treatment at 300 seconds were $0.014 \pm 0.005$, showing the rapid decrease in deoxygenation of hemoglobin when compared to the control group. On the other hand, the average relative changes in $\left[\mathrm{HbO}_{2}\right]$ were $0.003 \pm 0.002$, which represents the rapid recovery of hemoglobin oxygenation to the baseline after laser irradiation when compared to the control group.

In figure 7 , the relative changes in $[\mathrm{Hb}]$ and $\left[\mathrm{HbO}_{2}\right]$ concentration for the one of the participants showed that $[\mathrm{Hb}]$ concentration increased after the exercise began while $\left[\mathrm{HbO}_{2}\right]$ concentration decreased as expected. Once LLLT was irradiated after the exercise, the concentrations of $[\mathrm{Hb}]$ and $\left[\mathrm{HbO}_{2}\right]$ recovered rapidly to their baseline levels. It is expected that the intrinsic auto-regulation ability in muscle vasculature increases blood flow to meet the increased need for delivery and removal [34]. Since muscle contraction by intensive exercise or in patients with muscular disorders

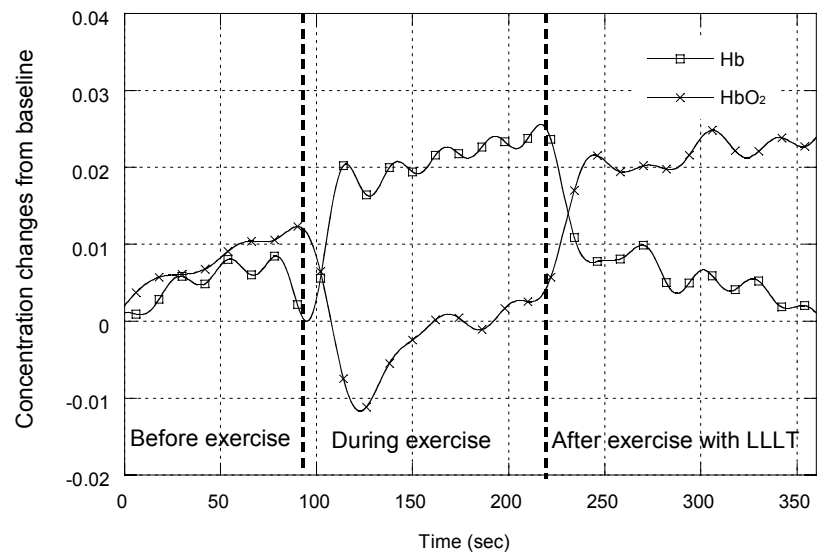

FIG. 7. The relative changes in $\left[\mathrm{HbO}_{2}\right]$ and $[\mathrm{Hb}]$ concentrations before, during and after exercise with LLLT application.

have common symptoms such as exercise intolerance, fatigue and stiffness by insufficient blood circulation, the reduction of oxygen supply to muscles increases the rate of muscle fatigue and inadequate removal of metabolic waste products [35]. The increased oxygen delivery after low-level laser irradiation could result in microcirculation increase, lactic acid concentration reduction and muscle fatigue recovery [13]. LLLT has been proved to simulate tissue chromophores and an increase in blood flow, inducing electronically excited states that modify their redox potential and catalytic activity [12]. E. C. Leal Junior et al. also found that LLLT seemed to attenuate skeletal muscle fatigue and to reduce the muscle damage caused by titanic contractions induced by electrical stimulation [36]. Passarella et al. found that laser irradiation generates an extra electrochemical potential and an increase of ATP synthesis inside the isolated mitochondria when compared with a non-irradiated control group [37].

The selected wavelength at $\lambda=830 \mathrm{~nm}$ based on Monte Carlo simulation in this study is especially attributed to a relatively oxidized form of cytochrome $\mathrm{c}$ oxidase that mediated the transfer of electrons from cytochrome $\mathrm{c}$ to molecular oxygen [38]. Kudoh et al. also observed a charge of Na-K ATPase in the rat saphenous nerve after treatment with a GaAlAs diode laser $(\lambda=830 \mathrm{~nm})$ and reported that this phenomenon may be considered very important for the attenuation of pain [39].

From the results of this study in the control group without low-level laser irradiation, muscle fatigue condition lasted for minutes after exercise. However, in the laserirradiated group, muscle fatigue recovered quickly to normal muscle condition after exercise. The developed combined system that contains low-level laser source and NIRS system in this study evaluated the effect of therapeutic modality and monitored the physiological condition during the low-level laser treatment in real time. This study may lend insight into the heat generation event occurring inside 
tissue layers depending on the wavelengths and help effective phototherapy, LLLT.

\section{CONCLUSION}

In this study, the wavelength dependence of penetration depth in tissue was evaluated using the Monte Carlo simulation and a combined system that contains low-level laser treatment source and non-invasive optical monitoring system for the effective treatment of muscle spasticity was developed. The Monte Carlo simulation results show that the greatest amount of heat generation was observed in deep tissue at $\lambda=830 \mathrm{~nm}$. Using the developed system, healthy subjects were used for measurements of tissue condition like $\left[\mathrm{HbO}_{2}\right]$ and $[\mathrm{Hb}]$ concentration changes during LLLT after exercise. The $\left[\mathrm{HbO}_{2}\right]$ concentration was significantly increased in the laser-irradiated group and these findings suggest that LLLT using $\lambda=830 \mathrm{~nm}$ may be of benefit in accelerating recovery of muscle spasticity. The developed system monitored the physiological condition of muscle spasm during the LLLT in real time and this system may also be applied to back-pain treatment/ monitoring, ulcer due to paralysis, and various myotonic conditions.

\section{ACKNOWLEDGMENT}

This research was supported by Basic Science Research Program through the National Research Foundation of Korea (NRF) funded by the Ministry of Education, Science and Technology (2009-0065758)

\section{REFERENCES}

1. D. V. Vaz and M. C. Mancini, "Muscle stiffness and strength and their relation to hand function in children with hemiplegic cerebral palsy," Developmental Medicine \& Child Neurology 48, 728-733 (2006).

2. R. L. Lieber, S. Steinman, I. A. Barash, and H. Chambers, "Structural and functional changes in spastic skeletal muscle," Muscle Nerve 29, 615-27 (2004).

3. R. A. Deyo, J. Bergman, and W. R. Phillips, "Drug therapy for back pain: Which drugs help which patients?," Spine 21, 2840-2850 (1996).

4. R. Chou, K. Peterson, and M. Helfand, "Comparative efficacy and safety of skeletal muscle relaxants for spasticity and musculoskeletal condition: a systematic review," J. Pain Symptom Manage 28, 140-175 (2004).

5. A. Hulme, W. J. MacLennan, and R. T. Ritchie, "Baclofen in the elderly stroke patient its side effects and pharmacokinetics," Eur. J. Clin. Pharmacol. 29, 467-469 (1985).

6. H. Mori, H. Ohsawa, T. H. Tanaka, E. Taniwaki, G. Leisman, and K. Nishijo, "Effect of massage on blood flow and muscle fatigue following isometric lumbar exercise," Med. Sci. Monit. 10, 173-178 (2004).
7. B. Drust, G. Atkinson, W. Gregson, D. French, and D. Binningsley, "The effects of massage on intra muscular temperature in the vastus lateralis in humans," Int. J. Sports Med. 24, 395-399 (2003).

8. Y. Y Huang, A. C. Chen, J. D. Carroll, and M. R. Hamblin, "Biphasic dose response in low level light therapy," Dose Response 7, 358-383 (2009).

9. D. A. Sussai, P. T. Carvalho, D. M. Dourado, A. C. Belchior, F. A. dos Reis, and D. M. Pereira, "Low-level laser therapy attenuates creatine kinase levels and apoptosis during forced swimming in rats," Lasers Med. Sci. 25, 115-120 (2009).

10. A. R. Medrado, L. S. Pugliese, S. R. Reis, and Z. A. Andrade, "Influence of low level laser therapy on wound healing and its biological action upon myofibroblasts," Lasers Surg. Med. 32, 239-244 (2003).

11. C. R. Hayworth, J. C. Rojas, E. Padilla, G. M. Holmes, E. C. Sheridan, and F. Gonzalez-Lima, "In vivo low-level light therapy increases cytochrome oxidase in skeletal muscle," Photochem. Photobiol. 86, 673-680 (2010).

12. T. Karu, "Primary and secondary mechanisms of action of visible to near-IR radiation on cells," J. Photochem. Photobiol. B: Biol. 49, 1-17 (1999).

13. Y. Asagai, A. Imakiire, and T. Ohshiro, "Thermographic effects of laser therapy in patients with cerebral palsy," Laser Therapy 12, 12-15 (2000).

14. E. C. Leal Junior, R. A. Lopes-Martins, F. Dalan, M. Ferrari, F. M. Sbabo, R. A. Generosi, B. M. Baroni, S. C. Penna, V. V. Iversen, and J. M. Bjordal, "Effect of 655-nm low-level laser therapy on exerciseinduced skeletal muscle fatigue in humans," Photomed. Laser Surg. 26, 419-424 (2008).

15. J. B. Walker, "Temporary suppression of clonus in humans by brief photostimulation. Brain research," Brain Res. 340, 109-113 (1985).

16. J. D. MacDougall, A. L. Hicks, J. R. MacDonald, R. S. Mckelvie, H. J. Green, and K. M. Smith, "Muscle performance and enzymatic adaptations to sprint interval training," J. Appl. Physiol. 84, 2138-2142 (1998).

17. S. Ahmaidi, P. Granier, Z. Taoutaou, J. Mercier, H. Dubouchaud, and C. Prefaut, "Effects of active recovery on plasma lactate and anaerobic power following repeated intensive exercise," Med. Sci. Sports Exerc. 28, 450-456 (1996).

18. T. O. McBride, B. W. Pogue, E. D. Gerety, S. B. Poplack, U. L. Osterberg, and K. D. Paulsen, "Spectroscopic diffuse optical tomography for the quantitative assessment of hemoglobin concentration and oxygen saturation in breast tissue," Appl. Opt. 38, 5480-5490 (1999).

19. S. Volianitis, P. Krustrup, E. Dawson, and N. H. Secher, "Arm blood flow and oxygenation on the transition from arm to combined arm and leg exercise in humans," J. Physiol. 547, 641-648 (2003).

20. M. Johns, C. A. Giller, and H. Liu, "Determination of hemoglobin oxygen saturation from turbid media using reflectance spectroscopy with small source-detector separations," Applied Spectroscopy 55, 1686-1694 (2001).

21. F. Costes, F. Prieur, L. Reasson, A. Geyssant, J. C. Barthelemy, and C. Denis, "Influence of trainging on NIRS muscle oxygen saturation during submaximal exercise," Med. Sci. Sports Exercise 33, 1484-1489 (2001).

22. T. Binzoni, L. Ngo, E. Hiltbrand, R. Springett, and D. Delpy, 
"Comsumption-temperature curves during rest and isometric exercise in human skeletal muscle," Comp. Biochem. Physiol. A 132, 27-32 (2002).

23. T. Karu, "Primary and secondary mechanisms of action of visible to near-IR radiation on cells," J. Photochem. Photobiol. B 49, 1-17 (1999).

24. C. M. Carvalho, J. A. de Lacerda, F. P. dos Santos Neto, M. C. T. Cangussu, A. M. C. Marques, and A. L. B. Pinheiro, "Wavelength effect in temporomandibular joint pain : a clinical experience," Lasers Med. Sci. 25, 229-232 (2010).

25. J. S. Dam, P. E. Andersen, T. Dalgaard, and P. E. Fabricius, "Determination of tissue optical properties from diffuse reflectance profiles by multivariate calibration," Appl. Opt. 37, 772-778 (1998).

26. J. I. Youn, "A comparison of wavelength dependence for laser-assisted lipolysis effect using Monte Carlo simulation," J. Opt. Soc. Korea 13, 267-271 (2009).

27. H. Lee, Y. U. Jeong, and K. F. Chan, "The advent of laser therapies in dermatology and urology: underlying mechanisms, recent trends, and future," J. Opt. Soc. Korea 13, 321-329 (2009).

28. L. Wang, S. L. Jacques, and L. Zheng, "MCML-Monte Carlo modeling of light transport in multi-layered tissues," Computer Methods and Programs in Biomedicine 47, 131-146 (1995).

29. C. S. Enwemeka, "Attenuation and penetration depth of red $632.8 \mathrm{~nm}$ and invisible infrared $904 \mathrm{~nm}$ light in soft tissues," J. Laser Ther. 13, 95-101 (2001).

30. A. Bozkurt, A. Rosen, H. Rosen, and B. Onaral, "A portable near infrared spectroscopy system for bedside monitoring of newborn brain," BioMedical Engineering OnLine 4, 1-11 (2005).

31. A. W. Subudhi, A. C. Dimmen, and R. C. Roach, "Effects of acute hypoxia on cerebral and muscle oxygenation during incremental exercise,” J. Appl. Physiol. 103, 177-183 (2007).

32. G. Yu, T. Durduran, C. Zhou, and A. G. Yodh, "Timedependent blood flow and oxygenation in human skeletal muscles measured with noninvasive near-infrared diffuse optical spectroscopies," J. Biomed. Opt. 10, 024027 (2005).

33. M. L. Snyder, C. Bork, B. Bourbon, and D. Trumbore, "Effect of helium-neon laser on musculoskeletal trigger points," Phys. Ther. 66, 1087-1090 (1986).

34. S. A. Spector, J. T. Lemmer, B. M. Koffman, T. A. Fleisher, I. M. Feuerstein, B. F. Hurley, and M. C. Dalakas, "Safety and efficacy of strength training in patients with sporadic inclusion body myositis," Muscle Nerve. 20, 1242-1248 (1997).

35. R. T. Hepple, J. L. Hagen, D. J. Krause, and C. C. Jackson, "Aerobic power declines with aging in rat skeletal muscles perfused at matched convective $\mathrm{O}_{2}$ delivery," J. Appl. Physiol. 94, 744-751 (2003).

36. E. C. Leal Junior, R. A. Lopes-Martins, A. A. Vanin, B. M. Baroni, D. Grosselli, T. De Marchi, V. V. Iversen, and J. M. Bjordal, "Effect of $830 \mathrm{~nm}$ low-level laser therapy in exercise-induced skeletal muscle fatigue in humans," Lasers Med. Sci. 24, 425-431 (2009).

37. S. Passarella, E. Casamassima, S. Molinari, D. Pastore, E. Quagliariello, I. M. Catalano, and A. Cingolani, "Increase of proton electrochemical potential and ATP synthesis in rat liver mitochondria irradiated in vitro by helium-neon laser," FEBS Letters 175, 95-99 (1984).

38. T. I. Karu, "Mitochondrial signaling in mammalian cells activated by red and near-IR radiation," Photochem. Photobiol. 84, 1091-1099 (2008).

39. C. Kudoh, K. Inomata, K. Okajima, M. Motegi, and T. Ohshiro, "Low level laser therapy : pain attenuation mechanism," Laser ther. 10, 3-6 (1988). 